\title{
Common Pool Resources Management Measures and Implementation Strategy of Skate Fishermen
}

\author{
Lee, Gyeong A \\ Institution for Marine and Island Cultures, Mokpo National University \\ lga2626@gmail.com
}

Publication Information:

Received 26 October 2019, Accepted 13 November 2019, Available online 16 December 2019

DOI: 10.21463/jmic.2019.08.2.05

\section{Abstract}

Who owns the sea? Fishery is an industry that uses common pool resources. Therefore, to realize the sustainable fishery, it should be operated in same context as the system operation for the common pool resources management.

Traditionally, the residents in fishing villages have developed fishing skills, adapting themselves to the unique ecological environment of their own region. However the government's uniform regulation rather disrupts the self-regulatory control system. The uniform regulation-oriented policies based on the idea that there should be rules forced from the outside may destroy the institutional capital that has been accumulated in specific area for a long time. People may make an institutional mechanism useful in solving the dilemma of common resources when they develop mutually shared norms and reciprocal behaviors living in the same environment for a significant period. From this perspective, it seems that it needs the autonomous solutions that can get over the tragedy of sharing, that is, organizing the group of shared resources users and setting design principle for the institutional mechanism.

Skate is a symbolic fish for Heuksando Island in Korea, skate catching was once at the verge of extinction due to exhaustion of resources, but nowadays it is leading the vitalization of the local economy thanks to the government management, support of the local government and efforts of local residents to restore resources. This paper will examine the management method put into practice to maintain the fishing community in crisis and to restore the fishery resources. The recognition on the resources shown in autonomous management is also our attitude toward the common pool resources.

\section{Keywords}

Common pool resources (CPR), Skate catching, TAC, Autonomous management, Sustainability 


\section{Introduction}

The natural environment of islands and fishing villages is slightly different by region and different fishing techniques and fishing methods are required according to its ecological and environmental characteristics. Fishermen have created and used the production techniques and tools required for their environment in the fishing and formed their own community norms.

Korean fishing villages have unique traditional norms different from those of farming village and it is the fishing village cooperatives. Fishing villages are created along the sea, which is common pool resources, and its resources are shared by fishermen. Fishing village cooperatives own the fishing ground, the common pool resources of the village in the form of collective ownership, and use the resources for production to generate income. It may take the form of co-production and co-distribution or it may be divided into areas for individual use.

However, the problem is that the marine environment is undermined to the extent that it cannot be recovered and the resources are being exhausted due to reckless development and use for the characteristics of common pool resources. In the early 1990s, the cods, which were very popular fish in Europe and North America, already encountered the same problem. The resources dropped dramatically due to overfishing in the Grand Banks of Newfoundland, Canada, one of the world's largest cod fishing grounds. Cod was the symbol of New England but it could not keep its image anymore as the fishery industry collapsed.

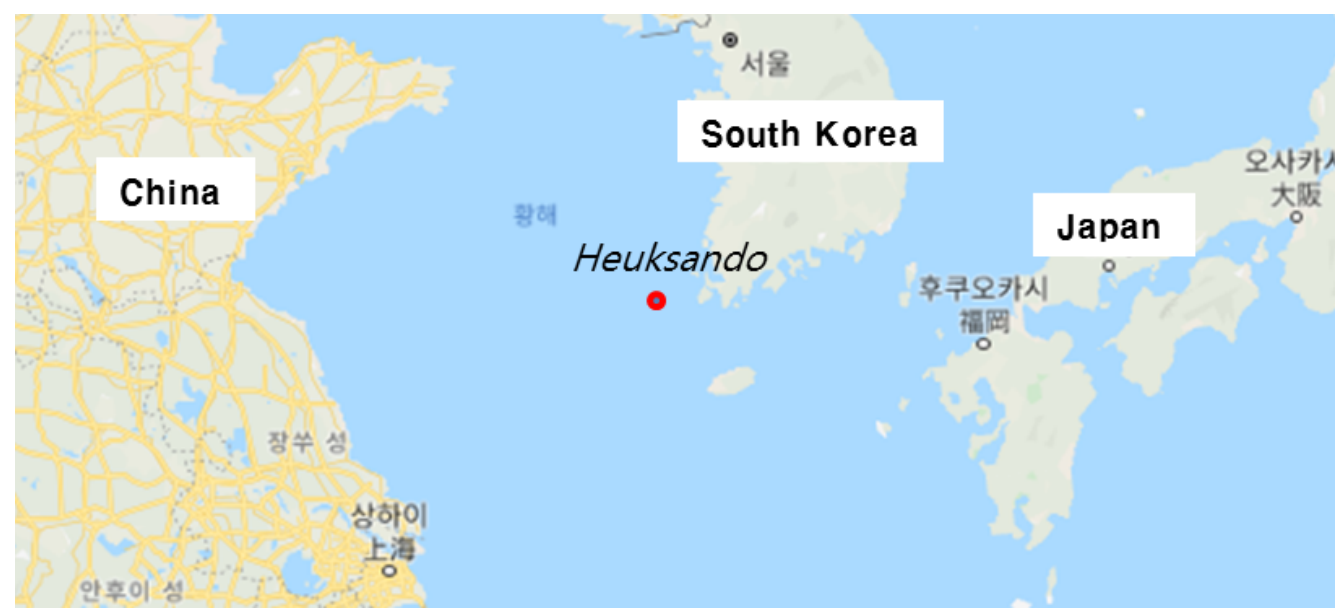

Fig 1. Location of 'Heuksando' Island

In general, overfishing ${ }^{1}$ means catching or collecting fish to the extent that the ability to be restored to original number of population is lost. Traditionally, the fishermen have caught only the fishes that can restore their population and collected fishes to the extent that they can obtain certain amount of benefits or appropriate level. However, after industrialization, commercial fishing activities have increased, the traditional fishing method disappeared. With the inflow of large capital, the performance of fishing boat has improved and the size of the boat has become bigger. The excessive trawl fishing ${ }^{2}$, which catches even baby fishes, has been on the rise, resulting in acceleration of overfishing. 
With the adoption of modern technology and equipment, intensifying competition over fishery resources and reckless overfishing led to exhaustion of fisheries resources, which have been regarded as self-renewable resources. The destruction of habitats in fishing ground and the reduction of fishing resources are the result of overuse of common property resources, not to mention the 'Tragedy of the Commons' by Hardin (1968).

This paper intends to solve the tragedy of common property resources in a way that the residents voluntarily form and agree on orders. This is the third mechanism proposed by Ostrom (2010). This study is intended to examine the ways in which people who share the fishing ground have a sense of unity and establish a new order for the community considering that crisis of the community as their own crisis.

\section{Theoretical discussion}

The fishery production in littoral sea of Korea has been reduced after recording 956,000 ton in 1972 and reaching its peak at 1.73 million ton in 1986. In 2016, the fishery production in littoral sea of Korea has been decreased less than 1 million ton for the first time in 44 years (www.mof.go.kr/statPortal). The reason for the decrease in the fishery production in littoral sea is not only by the climate change and the pollution in fishery ground environment but also by the development of fishing technology and large ship, which were introduced to increase fishery production volume. The introduction of the latest technology for competitive fishing has resulted in overfishing and exhaustion of resources. Of course, it is very clear that all the causes such as reduction of existing fishery ground by the Korea-Japan, Korea-China and Korea-Russia fisheries agreement according to the declaration of exclusive economic zone, indiscreet competitive fishing operation with the fishing boats of neighboring countries, illegal fishing operation by that and the contamination of coastal ecosystem, etc. caused the exhaustion of fishery resources.

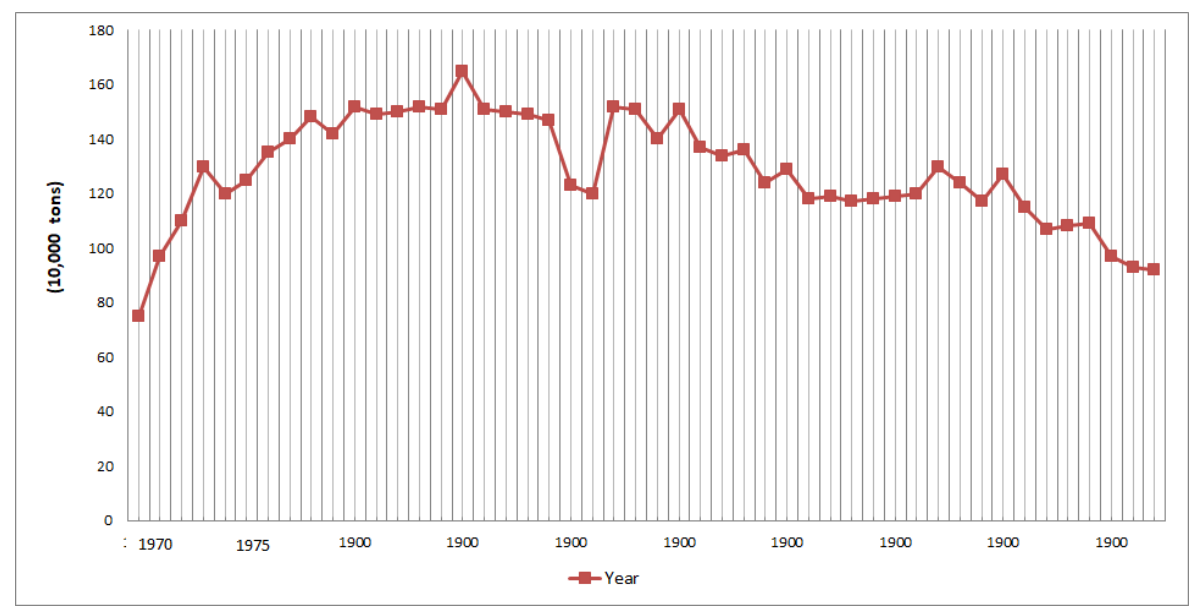

Fig 2. Fishery Production in Littoral Sea (1970 2016). (Source: Korea Fisheries Resources Agency)

Who owns the sea? Fishery is an industry using the fishery resources, the common pool resources. Therefore, the fishery industry should be in line with the system for common pool resources management in order to realize sustainable 
fishery industry. Korea established the Fishing Ground Management Act ([Law No. 14739, Mar. 21, 2017, partially revised]) to specify matters necessary for the efficient preservation and use of fishing ground for the purpose of improving productivity of fishing ground and increasing income of fishermen by preserving and improving fishing ground environment and building the foundation for sustainable fishery production. However, it is not easy to manage and control fishing ground due to its nature. For the characteristics of its nature of fishing, which is conducted on the sea, far from surveillance system, the crackdown is not easy, which results in disputes over fishing area, the fishing operation using illegal fishing gears and the violation of period that fishing is prohibited. That is because the tragedy of the commons works in marine resources.

Common property resources refer to the natural resources and the artificial facilities, for which large number of people have a joint ownership. Common goods or common pool resources refers to the natural resources and artificial facilities owned jointly by multiple individuals and are defined as the natural resources and artificial facilities shared and commonly used by multiple individuals and potential users of the resources cannot be excluded or hard to be excluded. They are defined as natural resources or artificial facilities where increased use of one individual is subtracted from total amount of resources that can be used by others (Ostrom, 2010: 70 75, Lee Myeong Seok, 2004). Ostrom distinguishes the common pool resources from the public goods pointing out the nature of reduction and competition. Even though one person uses the public goods, the amount of public goods that can be used by other people are not reduced and accordingly, users do not need to compete over resources. However, the common pool resources are reduced when a person uses and users inevitably compete over resources.

The skate catching, which is discussed in this paper, is conducted in the middle of the sea. Accordingly, significant amount of cost is incurred to prevent potential beneficiaries from fishing. In addition, it has characteristics of rivalry, particularly, the subtractability as the use of resources by one party reduces the production of other party. As such, it can be said that skate catching satisfies all the characteristics as common pool resources. In other words, in the aspect that the fishery resources have the characteristics of the common pool resources, in the perspective of rivalry and exclusion, it has characteristics of rivalry but does not have characteristics of exclusion. That is, it has a possibility of exhaustion due to rivalry among users but because of the characteristics without having exclusion, the number of users cannot be restricted. As a result, since the users opt for betrayal strategy rather than cooperative strategy if it are left as it will be exhausted after all (Hardin, 1968).

In this collaborative work zone, the individuals compete with each other to maximize their own profits and eventually, resources are exhausted. If individuals pursue their own interests excessively, the common pool resources will be destroyed and extinct in the long term. Therefore, if the fishery resources, which should be used by all community members, are left in the market function that claims the private interest, there is a risk that the resource would be exhausted as the current generation overuses them. We have to approach the structural problem of 'competition among individuals' from the personal problem by making the structure of 'selfishness of individuals and the competitive environmental destruction by that'.

Thus, Ostrom (1990) has proposed the solution by civil society community as an alternative. Ostrom argues that it may be more efficient in using common pool resources when the government leaves ownership to the members of the common poor resources to distribute the resources naturally at their discretion rather than the case where the central government strengthens its ownership intervening it in the way that it works in the market (Ostrom, 2010). The common pool resources problem can be solved rather smoothly when stakeholders are gathered to make a consensus on the system that restraints the right to use. According to the alternative proposed by Ostrom et al., the formation of this 
shared consciousness usually requires time for members of a certain group to become active for a long time to establish a shared consciousness. Ostrom gave a light on the fact that the individuals identify their own interests with the interest of the community by any reason whether by the education or it is stuck in their mind culturally and when they utilize the common pool resources imposing self-regulation considering the public perspective, the tragedy of the commons may not occur.

This paper intends to show the successful case of managing common pool resources by the organization of the offshore longline fishery related to skate catching in Heuksando Island, Shinan-gun, Jeollanam-do, Korea. It is true that government-led fisheries management has contributed a lot to the development and maintenance of fisheries, but that approach showed limitation and it is strongly requested to find a way to supplement that approach. The actual meaning of autonomous fishery resources management should be considered to be co-regulation between the government and the private sector. Here, co-regulation refers to joint regulation by the private sector and the government in addition to the co-regulation with fishermen.

It is the work of confirming that self-management by the community is leaded to the preservation and sustainable use of environment together with the accommodation of the institutional management policy by the government. In particular, the successful management of the common pool resources is possible when the mutual relationship with the responsibility among the people, society and nature is established based on the inherent attribute of the community in addition to the compliance with existing systems.

This study will examine the positive impact of the communal system run by offshore skate (scientific name Raja pulchra) fishing organization on the efficient use and the management of resources. This is in line with Maria Mies (2013) who found the core factor of successful management of common pool resources in the 'Community'.

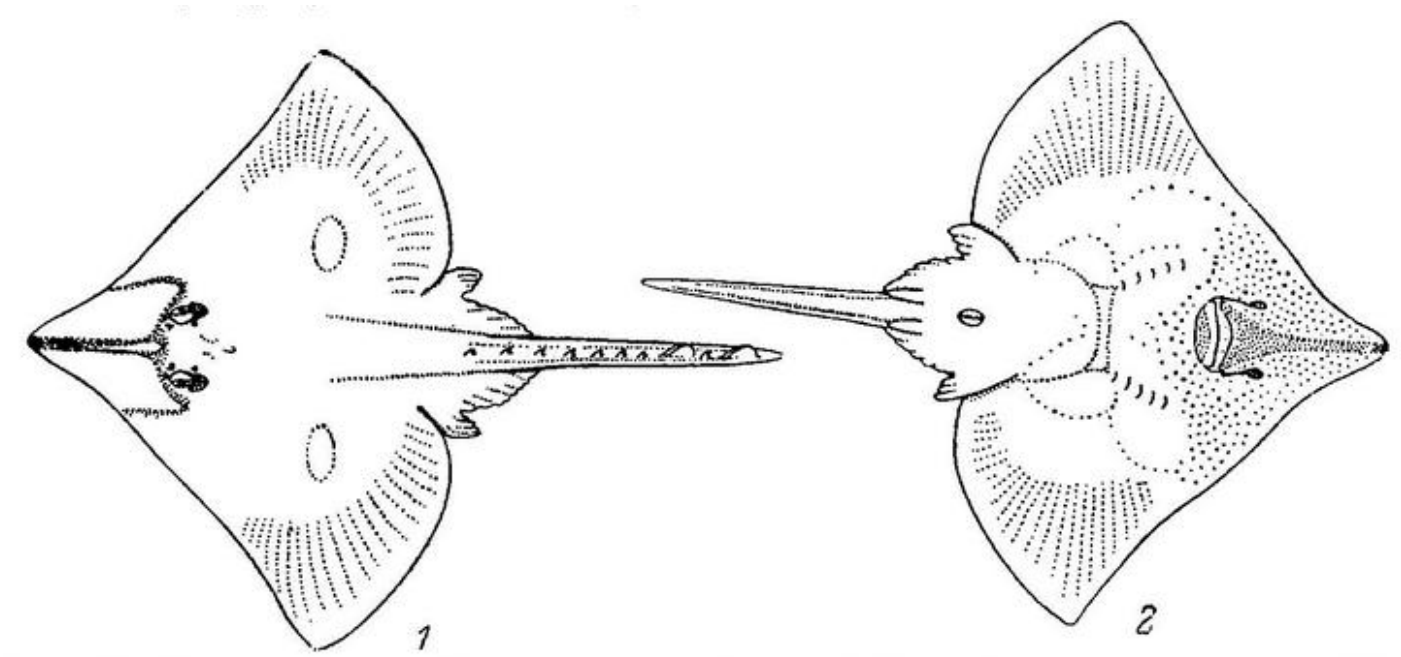

Pис. 79. Raja pulchra - Изящный скат. Длина 300 мм. Тип. Циндао. (Liu, 1932). Схематизировано.

1 - вид сверху; 2- вид снизу.

Fig 3. Skate (scientific name Raja pulchra) 


\section{Management of Common Pool Resources by Skate Fishermen and Implementation}

Fisheries are characterized by frequent conflicts of interests related to various laws and systems which are different depending on target fish, fishing gear, size of fishing boat and fishing ground. Although the Fisheries Act provides certain restrictions on the fishing activities, it is hard to support just one party as the interests of many groups are intertwined intricately. With regard to restrictions and conditions for permission on fisheries, many and complex conditions for obtaining permission made it difficult for fishermen to comply with applicable laws, resulting in many illegal fishing activities. Many complicated conditions for permission regarding fishing zone, fishing gear, fishing boat and catches are causing illegal fishing (Eum Seon-hee, 2018) by regulating the autonomy of fishermen excessively leading to exhaustion of resources.

The crisis caused by exhaustion of fishery resources is well revealed in the increase of the imported fishery products. As shown in Table 1, the import of fishery products has increased rapidly except the temporary decrease during financial crisis. The import of fishery products increased by more than 2 times in 2002 than 1995 level and 3 times in 2008 and more than 6 times in 2017. The increasing trend of fishery product import amount is partly because of the increase in the public consumption of fishery products but ultimately because of the reduction of fishery resources caused by overfishing amid fierce competition over fishery resources.

Table 1. Trend of Fishery Products Import Amount

\begin{tabular}{|c|l|l|l|l|l|l|l|l|l|l|}
\hline Year & 1995 & 1996 & 1997 & 1998 & 1999 & 2000 & 2001 & 2002 & $\ldots$ \\
\hline Import amount & 842,808 & $1,080,457$ & $1,045,474$ & 587,481 & $1,178,968$ & $1,410,598$ & $1,648,372$ & $1,884,417$ & $\ldots$ \\
\hline Year & 2008 & 2009 & 2010 & 2011 & 2012 & 2013 & 2014 & 2015 & 2016 & 2017 \\
\hline Import amount & $2,957,620$ & $2,717,296$ & $3,233,673$ & $3,971,055$ & $3,781,315$ & $3,685,428$ & $4,322,435$ & $4,396,983$ & $4,649,419$ & $5,135,923$ \\
\hline
\end{tabular}

Source: Statistical data of Ministry of Oceans and Fisheries

As shown in table above, the import of fishery products is likely to increase when we cannot manage our common fishing ground properly. Therefore, it is absolutely necessary to manage resources in order to prevent exhaustion of fishery resources and destruction of fishing ground.

Raja pulchra, which is mainly caught near the southwest coast of Korea, is the fish belonged to Rajidae, and is a representative fermented food in Korea. Originally, it was a fish enjoyed by ordinary people with rice wine as the price was affordable. Since it has unique sweet taste and it is not abundant, the price has been raised gradually and it became a premium kind of fish enough that the price reached 400,000 to 1.3 million won per fish. Especially, Raja pulchra caught near Heuksando Island became premium brand enough that it became the symbol of Heuksando Island. At present, Korea distinguishes between Raja pulchra and Okamejei kenojei. Since today it cannot meet its demand, it is imported from Chile and Argentina and most of the skate distributed in Korea is imported. 
Total population of Heuksando Island is 4,255, of which 1,489 are involved in fishing. Among 671 fishing boats licensed, only 6 boats are for catching skate. Until 1990s, about 30 fishing boats of Heuksando Island were catching the fishes in the skate fishing ground but fishing boats from outside came to catch skate and overfishing of skate occurred due to competition. The area near the coast of Heuksando Island is more than $80 \mathrm{~m}$ deep, which is suitable for skate to live. Catching skate is conducted for about 8 months from October to May the following year. However, about 50 boats come to this area from outside and illegal fishing boats from China come to this area resulting in exhaustion of resources. In the end, the stock of skate became exhausted and cheap skate is imported from foreign countries. As a result, many skate catching boats changed its license to catching shrimps or gave up fishing operation. In 1996, the number of skate fishing boat was 25 but the number decreased to 2 in 1996 and 1 in 1997.

By the decline of the skate fishing, the local economy of Heuksando Island has been stagnated. Catching skate is not only for economic benefits of ship owners and crews. It is related to many stakeholders that have an impact on the local economy including suppliers of food and goods for shipping, people who repair fishing gears (net), intermediary, wholesalers and retailers of skate, restaurants and accommodation business using skate.

Fortunately, the skate catching, which influenced on the economy of Heuksando Island, was revived in the mid 2000s. It was possible thanks to the efforts of the government, local government and fishermen to restore the community. That is, it started from systemic management of common pool resources. Managing the common pool resources was possible firstly by the surveillance and the management of illegal fishing by the government, secondly by the resources management strategy of local government and thirdly by the implementation strategy to keep the fishing ban period by fishermen on a voluntary basis.

First, the government cracked down on trawling fisheries and Chinese boats, which are conducting illegal fishing. Trawl fishing boats exhausted fish stock by using net to catch all kinds of fish on the floor and cut off the fishing line to catch skate, causing serious damage to fishermen. The government compensated the trawl fishing boats to reduce the number of such boats. The maritime police consistently cracked down on Chinese boats that invaded the exclusive economic zone (EEZ). Chinese fishing boats were not only catching fish but also fishing illegally causing damage to the fishery from lost fishing gears and devastation of skate fishing ground.

Illegal fishing is not limited to offshore of Korea. It has become a global concern. Internationally, this fishing is called IUU fishery and it is managed by classifying into the illegal, unreported and unregulated fishing. Efforts are being made at the national and international level to eradicate such type of fishing. Because the continuation of this kinds of fishing ultimately promotes the excessive use of fishery resources and leads to overfishing. With strong crackdown measure, the resources started being restored and preserved slowly.

The second is the strategy of the local government. Shinan-gun, which governs Heuksando Island, conducted projects to support preservation and transfer the skate fishing in preparation of the disappearance of Heuksando skate when the last skate catching boat gave up fishing at that time. The local government paid 30 million won for purchasing fishing gears and fuel to the owner and captain of the boat called Cheongshin (10 ton-class) (male, age: 50 at that time).

Support was provided to continue the stake catching and with the interest and support from the local government, the number of skate catching boats was increased from 2 to 4 in the following year.

One of the outstanding resources management strategies of the local government was to designate skate as species subject to TAC. With gradual increase of exhausted skate resources, the number of skate catching boats began to 
increase and in 2009, the local government applied for designation of skate as TAC item. Initially, there was a conflict with fishermen. TAC refers to the total allowable catches a year by each species. It is an important resources management tool but there was strong opposition from fishermen because TAC limits the number of catches. It was very difficult for captains and fishermen, who have caught the fish without any consideration, to understand this approach. But fishermen finally accepted the implementation of TAC, which determines the total annual allowable catches based on scientific resources assessment and socioeconomic factors and allocates and manages the quota by boat based on the fish catching record of fishermen and the boat size in the long-term perspective, and the effects of such approach became visualized.

The information on Heuksando skate production shows that 193 tons of skate were caught by 6 boats in 2018 and the consignment sales amount was 48.67 million won. The consignment sales amount, which has been decreased from 13 million won in 1991 to 4.3 million won in 1995, began to increase gradually after cracking down on illegal fishing boats and reducing the number of fishing boats. The amount started to increase gradually after mid 2000s. The amount of catches is restricted by designating skate as TAC item and implementing quota system in 2009.

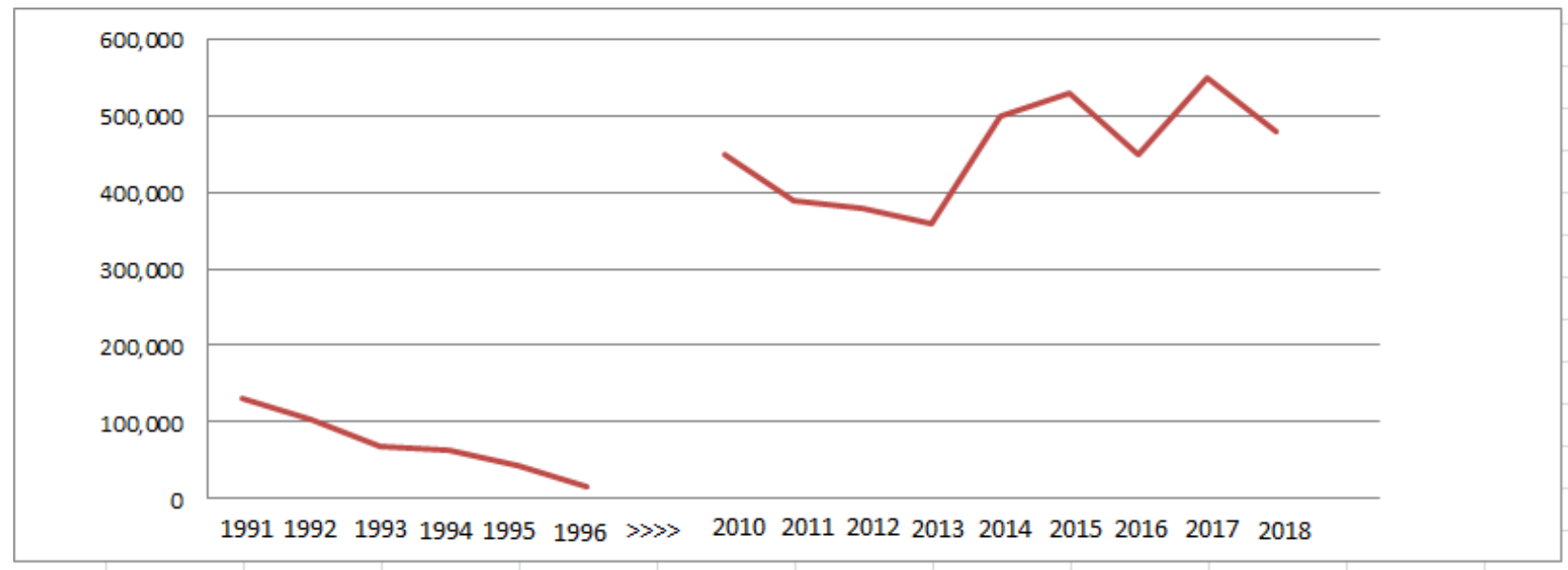

Fig 4. Consignment sales amount of Raja pulchra (1991 2018). (Source: ShinanSoohyup, Heuksan Branch), Amount (unit: 1,000 won)

Unlike ordinary fish, which produces tens of thousands of eggs at a time, Raja pulchra as very low reproduction capabilities as the number of eggs produced per time is very low. In particular, overfishing of non-adult fish, devastation of fishing grounds and changes in the fishery environment reduced the amount of resources, leading to sharp increase in the price of fish. Therefore, one of the policies to restore fishery resources for species, which the share of many not-fully grown fishes is high, is to ban the fishing of the species less than certain length for a certain period, and skate was included in it. The spawning period of the Raja pulchra is throughout the year (major spawning period: Apr. to June, Nov. to Dec.) except for July and Aug. The period of prohibiting the catch was set from June 1 to July 15 and it was regulated to prevent catching of fish smaller than $63 \mathrm{~cm}$ for female fish and $58 \mathrm{~cm}$ for male fish.

One of the unique characteristics of skate catching in Heuksando Island is fishing gear. Long line fishing, which is used for catching skate, used the sea eel as a bait, but was changed to the fishing without a bait. The fishing without bait is similar to the long line fishing but there is no barb in the fishing hook. 

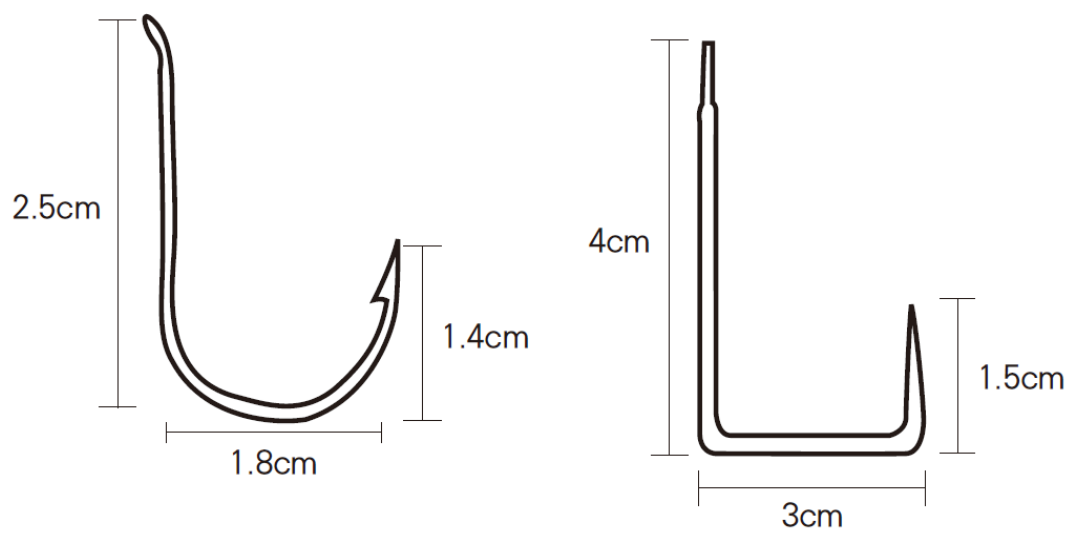

Fig 5. Long line fishing needle in the past (left) and current fishing needle without bait (right)

Fishing without bait was adopted from Japan. It was used in Incheon initially and transferred to Heuksando Island around 1980. With the change of fishing method from fishing with bait to fishing without bait earnestly, the stagnant skate catching became vitalized. Fishing without bait has a advantage in the aspect that it can save the bait purchase cost and the labor to put bait onto needle. As the bait is not used, it has aspect of protecting the fishing ground. The adoption of this fishing method shows the appropriate technology for the environment. The fishing with bait (long line) is also fishing method identified the ecosystem of skate. Fishermen is applying traditional knowledge (TK) to the fishing activities including identification of the skate habitat and the direction of tidal current. They catch the skate relying on the experience and the traditional knowledge than the state of the art fish group detector.

The reason why Heuksando Island made an effort to continue skate catching is that many entities are involved in skate catching. They have made the effort so that diverse entities are not collapsed down such as the merchants who supply food and fishing gear required in fishing boat, local residents who manage the long line fishing needles and broker for auction and the skate wholesalers and retailers to the restaurant using skate and the accommodation business owner. What is most important is that fishermen made an effort to keep all these rules strictly. It is right that the fishermen establish and enforce the rules using traditional knowledge passed down for generations by themselves.

For the characteristics of fishing operation that is conducted in the middle of the sea, the surveillance and the supervising the fishing are difficult. To overcome this problem, it is necessary to conduct the surveillance and the supervision on the land in parallel. Of course, if the principles are kept properly, there is no need for surveillance or management. Fishermen are following the rules of TAC, fishing prohibition period and other regulations. The systematic reporting system from consignment sales to next stage distribution channels in the land is well established. Based on this, caches are monitored and consignment sales and sales amount are monitored and mutually checked in the port to provide correct information.

In this regard, Norway also has three mandatory reporting: logbook, landing report and sales report. Norwegian catch and landing reports and sales reports are managed by an integrated system. Likewise, in Heuksando, accurate figures for TAC volumes are reported and managed by the fisheries cooperative. They keep the autonomous management fishing thoroughly in order not to commit to illegal distribution by cheating TAC volume or catching the fishes less than prohibited size in secret. 
Table 2. Comparison between before and after applying TAC to skate catching

\begin{tabular}{|l|l|l|}
\hline \multicolumn{1}{|c|}{ Description } & \multicolumn{1}{c|}{ Before TAC application } & \multicolumn{1}{c|}{ After TAC application } \\
\hline License & Offshore, coastal & Offshore, coastal \\
\hline Boats & $25 \sim 30$ boats & $6 \sim 7$ boats \\
\hline Method & Fishing with bait & Fishing without bait \\
\hline Catches & No limitation & Restricted TAC volume \\
\hline Prohibition period & No limitation & 45 days (June 1 July 15) \\
\hline Distribution and sales method & Individual, intermediary merchants & Consignment sales of Soohyup intermediary merchants \\
\hline
\end{tabular}

As the number of catches of skate has gradually increased in the results of applying TAC, now six fishing boats are in operation. They actively participate in the policies implemented by governments and local governments. In addition, the area of Gageodo Island in Heuksan designated as a marine protected area in 2012 discharges fishery seedlings every year and protects and fosters the resources through the fishery environment purification project. In addition, the residents are introducing diverse strategies for the restoration of fishery resources demanding the injection of artificial reefs actively. In fact, as the government-led fisheries management takes the fishermen as direct control subject, the main agent of using the resources rather than resources themselves, the fisheries resource management subject should be the fishermen who are benefiting substantially. It has given meaning to the maintenance of the community so that it does not commit the previous mistakes of placing it in the crisis of the dissolution of the community because of the exhaustion of the fish stocks. This is the reason why the fishermen should aim to increase their income through effective resource conservation, proper production and the maintenance of proper fish prices through autonomous fishery management.

In particular, the exhaustion of fishery resources is showing the trend that the resources are continuously decreased due to indiscreet overfishing, climate change, development of fishery technology, pollution of fisheries environment, and so on. The introduction of state-of-the-art fishery equipment, such as the enlargement and modernization of fishing boats, etc. is the representative cause of reducing the resources, and the rapid development of such fishery technology has spurred the exhaustion of fish stocks and the devastation of fishery ground.

\section{Policy suggestions}

Traditionally, the residents of fishing villages have developed fishery skills adapting to the unique ecological environment of the area. However, in the recent fishing community, the community is being collapsed due to over-depopulation and aging of the population, and the fishery also causes the decrease of the fishery income by the exhaustion of fishery resources, etc. and the social infrastructure is being disrupted.

The dramatic development of fishery technology globally has spurred the exhaustion of the resources and the devastation of the fishery ground. The biodiversity crisis has become a global social problem in the situation where the ecosystem is suddenly destroyed due to reckless development for the environment such as land reclamation, etc. the 
environmental pollution such as oil pollution incident, and the climatic change such as rising sea water temperature. Especially, due to the changes in fishery conditions such as fishery agreements with neighboring countries, the problem of fishing ground reduction is added, and the fisheries industry in Korea has been brought into a crisis. In addition, as the United Nations Convention on the Law of the Sea (UNCLOS) has become effective, the needs to create the futureoriented coastal fisheries resources to stabilize fisheries production and fisheries management permanently come up to the surface.

Fishery resource management should be done autonomously by the fishermen themselves. For the characteristics of fishery resources, which is the common pool resources, using it and the exhaustion are easy, but the management and recovery are not easy. Since if the common pool resources are not managed, it results in the tragedy, the restoration of fishery resources for the future generations should have persistence, not one-shot.

The fishery resource development project, which started as an alternative, is implemented to create fishery resources such as installation of artificial reef, installation of sea ranch, installation of sea forest, and discharge of fishery seedlings, etc. Above all, since the overfishing and contamination of coastal ecosystems are the big problem in the aspect that they are not only reducing the quantity of resources but also reducing the ratio of grown fishes and the reduction of the nutritional level of the catches due to habitat and destruction of spawning grounds, the baby fish management is important than anything else.

Reducing the baby fishes means the lowering the quality of the coastal ecosystem, which in turn makes recuperative power of the fishery resources difficult. The joint effort of government, local governments, and fishermen are required to protect the fishery resources but the most important is the cognition of the fishermen themselves. It is necessary to place the meaning on the intrinsic property and value of the fishermen's community, not for the individual's selfish interest, such as catching immature fish recklessly and catching the fishes disregarding the prohibition period, etc.

It is a matter of time before a fishing village is devastated when it lacks owner consciousness. To prevent ghost fishing ${ }^{3}$, where fish dies due to discarded fishing gear, it is necessary to move toward the eco-friendly fishing to protect fishing ground.

Environmentally friendly fishery is the fishery using the fishing gears to reduce the incidental catch and dumping and refers to the fishery more selective, less environmental destruction when the fishing gear is lost or swept away and fishery using relatively small fish gears. It is not easy for the fishery, which has been maintained as a modern technology and practice fishing industry, to transform to an environmentally friendly fishery.

It is important to note that quota is applied to the licensed fishing boats for skate fishing and that the problem is that other boats catch the skate in the form of catching various kinds of fishes. They do not have a permission to catch a skate, but it is often that they often catch using the net and deal illegally, not on the official consignment sales stand.

As the fishery environment is getting worse, it is necessary to switch the fishing industry to the autonomous regulation by the fishermen themselves, not by the government. A system should be established to allow fishermen themselves to manage their resources and to engage in the fishing grounds purification activities moving away from the existing government-led fisheries management system. 


\section{Endnotes}

1. If the fishing is made beyond the maximum restoration ability of the fishery resources, rapid exhaustion of resources occurs. It is called overfishing. The typical sign of overfishing is that even when the fishing effort is decreased, the total catch is reduced and the old fishes are reduced and the young fishes are increased (Dictionary of Marine terms. http://ko.oceandic.wikidok.netwpd/5850d2acfe0322096283ffa9/View)

2. Small trawl fishing, which is one of the major causes of overfishing, is so called excessive trawl fishing that catches all kinds of fishes including baby fishes putting and dragging the net on the sea floor. Since this fishing method indiscriminately catches young fishes, it is considered as a main culprit of decreasing the fishery resources and the destroying the costal ecosystem. In particular, in case of the fishes releases to conserve the fishery resources in the coastal area, the damage would be great if the crackdown is not made properly.

3. It is estimated that the waste fishing gears in the coastal waters of Korea reaches to 44,000 tons per year, and most of them are left in the sea. The amount of damage caused by ghost fishing, which the fishes die caught by the waste fishing gear, reaches to about 370 billion won per year.

\section{References}

Eum Seon-hee, 2018. Improvement of permission system for offshore fisheries in response to changes in fishery conditions, Korea Maritime Institute.

Hardin, G., 1968. The tragedy of the commons, Science. 162(3859), 1243-1248.

Hong Sun-Kee, 2019. The Role of Ecological Diversity and Identity for Sustainable Development of Islands, J. Marine and Island Cultures 8(1). Lee Myeong Seok, 2004. Institution, Heterogeneity, Trust and Possibility of Cooperation in Social Dilemma, Korean Public Administration Review Vol.38 No.1.

Mies, M., Veronika B.T., 2013. The Subsistence Perspective: Beyond the Globalized Economy, Zed Books.

Ostrom, E., 1990. Governing the Commons: The Evolution of Institutions for Collective Action, Cambridge University Press, Cambridge.

Ostrom, E., 2010. Beyond Markets and States: Polycentric Governance of Complex Economic Systems. American Economic Review, 100 (3): 641-72. DOI: 10.1257/aer.100.3.641 